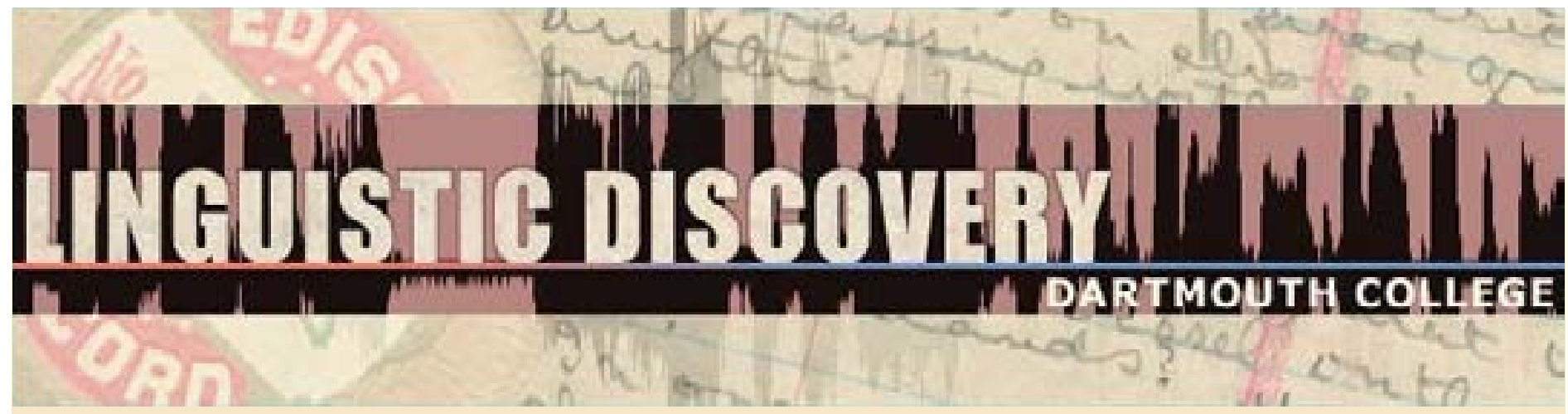

\begin{tabular}{|l|}
\hline Volume 1 \\
Issue 2 \\
2002 \\
\hline
\end{tabular}

\title{
Vowel Harmony in Oroqen
}

\author{
Lindsay J. Whaley \\ Dartmouth College
}

doi: 10.1349/PS1.1537-0852.A.201

url: http://journals.dartmouth.edu/cgi-bin/WebObjects/ Journals.woa/1/xmlpage/1/article/201

\section{Linguistic Discovery}

Published by the Dartmouth College Library Copyright to this article is held by the authors. ISSN 1537-0852 linguistic-discovery.dartmouth.edu 


\title{
Problem Set: Vowel Harmony in Oroqen
}

\author{
Lindsay J. Whaley \\ Dartmouth College
}

Oroqen [orst $\left.\rho^{j} \varepsilon n^{\prime}\right]$ is a Tungusic language spoken by approximately 1,200 people in northeastern China. The data in this problem are taken from the Central dialect of the language. Due to language attrition among the Oroqen, the process of vowel harmony is being lost. Only in the language of older speakers does one find the full paradigm below.

Examine the following data and account for the vowel alternations that are found in the suffixes. NB: 1) in regular speech, stem final [n] deletes when followed by an obstruent; 2) the initial [w] of the accusative suffixes becomes [m] after nasals.

\begin{tabular}{|c|c|c|c|c|}
\hline Noun root & Diminutive & Dative & Genitive & Accusative Definite \\
\hline olo 'fish' & olo-xon & olo-du & olo-yI & olว-wo \\
\hline jinaxin 'dog' & yinaxi-xan & yinaxi-du & yinaxin-yI & yınaxin-ma \\
\hline bэj९ 'person' & bэjง-xэn & bงjง-du & bэjง-ni & bэjง-w૭ \\
\hline t fạku 'bowl' & t fạku-xon & t $\int a \eta k u-d u$ & $\mathrm{t} \int a \eta k U-\eta \mathrm{I}$ & t $\int a y k u-w o$ \\
\hline algan 'leg' & alga-xan & alga-du & algan-1j & algan-ma \\
\hline bэ:Su 'cloth' & bэ:Su-xon & bэ: $\int u-d u$ & 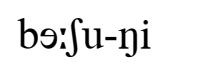 & bэ: $\int u-w o$ \\
\hline mowon 'silver' & mowo-xon & mowo-du & mowon-ni & mowon-mo \\
\hline$b^{\mathrm{j}} \varepsilon_{\mathrm{s}}$ 'month' & $\mathrm{b}^{\mathrm{j}} \varepsilon:-\mathrm{xan}$ & $b^{j} \varepsilon:-d u$ & $\mathrm{~b}^{\mathrm{j}} \varepsilon \mathrm{i}-\eta \mathrm{\eta}$ & $b^{j} \varepsilon:-w a$ \\
\hline tutuje 'dove' & tutuje-xən & tutuje-du & tutuje-ni & tutuje-wэ \\
\hline tubixi 'fruit' & tubixi-xən & tubixi-du & tubixi-ni & tubixi-w9 \\
\hline
\end{tabular}


Suggested Answer: The suffixes in these data are subject to vowel harmony with the final vowel of the root. The harmony always involves the feature ATR (advanced tongue root) [or alternatively, tenseness or RTR--retracted tongue root]. Thus, stems that have a [+ATR] vowel in their final syllable will appear with suffixes containing a [+ATR] vowel. Stems that have a [-ATR] vowel in their final syllable will appear with suffixes containing a [-ATR] vowel. This is the only harmony process for suffixes with underlying high vowels; hence, the genitive and dative suffixes only have two variants.

Suffixes that have non-high vowels additionally undergo a rounding harmony. Thus, stems that have a [+round] vowel in their final syllable will appear with suffixes containing a [+round] vowel. Stems that have a [-round] vowel in their final syllable will appear with suffixes containing a [-round] vowel.

One problem that many students will confront in this problem is how to treat the schwa. Often, they will have been taught that this sound is [-ATR] (or [-tense]), but in Tungusic languages the schwa patterns as the [+ATR] counterpart of [a]. If one treats schwa as [+ATR], the statement of harmony is straightforward. If students fail to see this, their statement of harmony will be disjunctive.

For advanced students, these data can also be used to discuss harmony within the roots. All vowels in a root must harmonize for [ATR]. For native vocabulary there is rounding harmony, though it will be for students to understand how it operates based on the forms above. The rounding harmony operates left to right such that a round vowel requires all vowels to its right also to be round. However, where [u] occurs, the process ceases (as can be seen in the final two stems above where rounding does not spread to the [i]'s and [e]). 